\title{
Gender Differences in Achievement in an Inquiry- Based Learning Precalculus Course
}

\author{
Thomas E. Cooper, Brad Bailey \& Karen S. Briggs \\ University of North Georgia, USA
}

•Received 12December 2014•Revised 19 April $2015 \bullet$ Accepted 3 August 2015

The authors conducted a two-semester quasi-experimental study in which each author taught a traditional lecture-based section of precalculus and a section using an inquirybased approach called a Modified Moore Method in which the students worked through and presented the course material. A common final exam was used to compare student achievement. The results were compared for the overall population and by each instructor. Gender proved to be an important variable with the females performing significantly better in the Modified Moore Method sections than their counterparts in the traditional sections while there were no significant differences for the males.

Keywords: precalculus, inquiry-based learning, gender differences

\section{INTRODUCTION}

There is an ancient proverb attributed to Confucius that reads: "I hear, I forget. I see, I remember. I do, I understand." The idea behind this saying is the driving force in many modern educational practices. Educational literature is filled with theories and approaches to teaching and learning based on the idea that a teacher-centered method, dominated by lectures and demonstration with rote drill and practice, is an ineffective way to promote meaningful learning. Problem-Based Learning, InquiryBased Learning, Process-Oriented Guided Inquiry Learning, Discovery Learning, and Experiential Learning are a few of the labels for widely practiced methods of instruction that share the common theme that students learn best when they are actively involved in the classroom. Proponents of these types of approaches often support their work with the constructivist theory of learning which asserts that each individual has a unique set of experiences and interactions with the world and must therefore construct his or her own knowledge (e.g., Cobb, 1994; Confrey, 1990; von Glasersfeld, 2003).

Student-centered teaching methods are certainly not modern inventions as we see from the centuries old proverb that opened this discussion. This saying was reportedly a favorite of mathematician Robert Lee Moore (1882-1974) who pioneered a teaching method that now bears his name, the Moore Method or

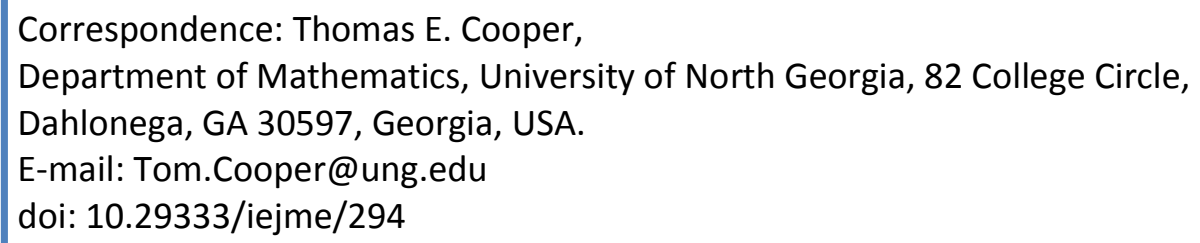


Moore's Method. Moore reportedly found as a student that he learned most effectively when he worked out proofs and results himself before seeing his teachers' presentations (Zitarelli, 2004). His experiences as a student encouraged Moore as a professor to develop courses in which there were no lectures or textbooks used to present material. In Moore's upper-level, proof-based mathematics classes, the students were given a set of definitions, axioms, and theorems and assigned the task of working through and presenting proofs to the theorems. According to descriptions given by his former students (Whyburn, 1970; Jones, 1977), Moore's classes were individualized and competitive with students instructed to speak to no one other than Moore about the problems, including their classmates. Moore believed that this was the best way to produce qualified research mathematicians, and his record as a doctoral advisor supports this view. Moore directed 50 dissertations, mostly at the University of Texas, and many of his students went on to have prolific careers as mathematicians. Readers interested in more detailed discussions of R. L. Moore, the Moore Method, and Moore's mathematical descendants should consult the works of Zitarelli (2004) and Traylor (1972).

The Moore Method is certainly not without its critics, and a common opinion is that a strict Moore Method may be appropriate for upper-level, proof-based mathematics courses, but such an approach would never work for lower-level courses with larger class sizes and less prepared, less motivated students. Holding to the principle that students will learn mathematics best by doing mathematics, several authors have presented less strict modifications of the Moore Method, collectively referred to as modified Moore methods (MMM). Chalice's (1995) modifications include having multiple students presenting simultaneously at the board to increase the speed of coverage, using easier exercises to make the material more accessible to weaker students, providing write ups of student work afterwards so that the students can pay more attention to discussions, and dividing the material into units with exams. Cohen (1982) tackled the problem of larger class sizes by having the students work and present solutions in groups, recommending class sizes of up to 25 students. W. T. Mahavier (1997) combined student problem solving and presentations with lecturing. Mahavier reports having success in a variety of lowerlevel classes such as algebra, trigonometry, and precalculus, but he argues that lower-level classes typically require more lecture time.

At the time of the study described in this paper, we could find no published empirical results comparing the effectiveness of an MMM to traditional lecturebased methods in lower-level collegiate mathematics courses. We were intrigued by the ongoing debate about whether direct instruction is more effective than inquirybase methods, and we were interested to see what would happen if we tried to implement our own version of an MMM in our precalculus classes, which typically range in size from 30 to 38 students. With funding from the Educational Advancement Foundation, we were able to conduct a quasi-experimental study (Reichardt, 2009) in which each of the authors taught two sections of precalculus; one using a traditional lecture approach and another using an MMM approach.

\section{THE TEACHER-CENTERED VERSUS STUDENT-CENTERED INSTRUCTION DEBATE}

In a 2006 issue of the Educational Psychologist, Kirschner, Sweller, and Clark, published an argument that direct instruction and worked examples are superior to the various forms of student-centered learning. Kirschner et al.'s primary argument is that problem solving with minimal guidance places too high a demand on a student's cognitive load for learning to occur. Kirschner, et al. write that the goal of 
learning should be to transfer knowledge into the long-term memory, and direct instruction is the most efficient way to do this. This article was controversial enough to spawn three responses and a counter response by Kirschner, et al. in a 2007 issue of the same journal. Hmelo-Silver, Duncan, and Chinn (2007) argued that Kirschner, et al. were ignoring the fact that Problem-Based Learning (PBL) and Inquiry Learning (IL) are supposed to be accompanied with scaffolding to prevent cognitive overload, and they cite empirical evidence that PBL and IL have led to increased learning over traditional methods. Most notably, Hmelo-Silver et al. cite a metaanalysis of the effects of PBL in which Dochy, Segers, Van den Bossche, and Gijbels (2003) found no significant effect when comparing traditional and PBL instruction on assessments of declarative knowledge, but they found a moderately positive, robust effect size favoring the PBL students on the application of knowledge. Schmidt, Loyens, Gog, and Paas (2007) agree with Kirschner, et al. that minimal guidance is ineffective, but like Hmelo-Silver et al., they argue that PBL is not the same as minimally-guided instruction, as guidance is provided by the structure of the problems posed and the questioning and feedback of the facilitators. These defenses of PBL could easily apply to the Moore Method or its modifications. While placing major responsibility on the students, the instructor in a modified Moore method class provides a tremendous amount of guidance through the carefully crafted sequence of problems and through questioning and leading discussions of the students' work.

The third criticism published addressing the arguments of Kirschner, et al. (2006) is also relevant to a discussion of the Moore Method. Kuhn (2007) writes that Kirschner et al. make their argument "without reference to any context of what it is that is being taught by whom and to whom" (p. 109). Kuhn argues that national and state standards in science education require that students learn inquiry skills and those inquiry skills cannot be taught through direct instruction. We take a similar stance about mathematics. If one believes that mathematics is a finite, fixed set of facts and algorithms and that one individual can pass such information to another by demonstration, then requiring students to work out details for themselves might seem like a waste of time. We, however, believe that mathematics is an evolving human process. It is an attempt by mankind to quantify and explain our interactions with the world around us. Mathematics is about critical thinking and problem solving. To be socially useful, mathematics needs to have agreed upon definitions, conventions, skills, and procedures, but those things are of little use without the knowledge of when and how to use them. Real-life problems do not look like the routine set of exercises found in many traditional textbooks, which often require little more than repetition of the procedures outlined in the preceding pages. Furthermore, adhering to a constructivist epistemology, we simply do not believe that one-way lectures, in which we profess our knowledge of a topic to students without their input and interactions, leads to understanding and retention.

\section{GENDER DIFFERENCES}

Though we were well aware of the extensive coverage that gender differences in mathematics achievement and attitudes and beliefs about mathematics have received in the educational literature, we did not begin our study initially expecting to find gender differences ourselves. However, as we taught our classes using an MMM, it became apparent that more males were exhibiting resistance to the method and a lack of participation, whereas more of the females in our classes came prepared with assignments and volunteered to present on a regular basis. As participation is a key component of success in a student- centered learning environment, we decided that we should include gender as a variable in our investigation. 
At the time of our study, we were aware of no literature reporting on gender differences in inquiry-based undergraduate mathematics, but after we had completed our study, a report was released (Laursen, Hassi, Kogan, Hunter, \& Weston, 2011) concerning a large scale investigation of inquiry-based learning (IBL) conducted by researchers at the University of Colorado Boulder in collaboration with three other universities. This study took place over two years and included qualitative and quantitative data from over 100 classes. In particular, the researchers collected self-reported information on learning gains from students in IBL classes using numerical and open-ended surveys and analyzed the data by gender. The analysis revealed that women in IBL classes reported higher gains than the males in the same classes across all of the self-reported measures, whereas the "women in the non-IBL classes reported statistically much lower gains than their male classmates in several important domains: understanding concepts, thinking and problem-solving, confidence, and positive attitude toward mathematics" (p. vi). The IBL report asserts overall that IBL courses can eliminate gender gaps by removing the stereotype threat and leveling the playing field. We think this hypothesis merits further investigation, and we believe that IBL methods such as an MMM can be effective even in a first year course such as precalculus. In the remainder of this section, we will summarize literature findings on the existence of gender gaps in mathematics and discuss proposed theories to explain why such gaps might exist and how these theories shape our expectations for MMM classes.

Whether there is a gender gap in mathematics achievement has long been a topic of interest to researchers. In a recent meta-analysis, Lindberg, Hyde, and Peterson (2010) reported that their initial search of three popular online databases returned tens of thousands of results related to gender differences in mathematics written in English between 1990 and 2007. Based on a set of criteria, including a comparison of mathematics performance and the necessary information for computing effect sizes, Lindberg, et al. analyzed 242 studies and concluded that males and females perform similarly in mathematics. Specifically, the meta-analysis revealed negligible effect sizes for gender differences in mathematical performance at the elementary and middle school levels along with small effect sizes favoring the males in high school $(d=+0.23)$ and college $(d=+0.18)$. The authors note that few of the studies included assessments involving high-level problem solving and for those that did include such items, the results favored the male students in high school $(d=+0.16)$ and the female students in college $(d=-0.11)$. While the meta-analysis provides encouraging evidence that wide spread achievement gaps between males and females may have dramatically decreased over the past two decades, the large quantity of published research clearly indicates that there are conditions which can lead to gender differences in achievement in mathematics.

Aside from achievement, there is considerable evidence that gender differences often appear in student perceptions and attitudes and beliefs about mathematics. In the late 1970s, Fennema and Sherman (1977) found a large number of attitudinal differences with males having more favorable attitudes toward mathematics than females. Others such as Betz and Hackett (1983) have found similar results with females having lower self-efficacy in mathematics than males, and many researchers report that students, teachers, and parents often stereotype mathematics as a subject in which males are more interested and more capable of success (Kiefer \& Sekaquaptewa, 2007; Li, 1999; Nosek, Banaji, \& Greenwald, 2002).

Several authors have presented theoretical arguments in an attempt to explain why gender differences may occur in mathematics. The most notable theories attribute differences to internal factors such as physiological (e.g., Benbow, 1988) and cognitive differences (e.g., Byrnes \& Takahira, 1993), external factors such as exposure to learning experiences (e.g., Fennema \& Sherman, 1977; Pallas \& Alexander, 1983) and social stereotypes (Steele, 1997), or some combination of 
these two types of factors. Byrnes (2005) argues that no explanation relying on a single source to explain gender differences is adequate. For example, biological explanations alone cannot account for the fact that most studies have revealed that gender differences in mathematics achievement do not occur prior to high school (Lindberg, et al., 2010).

The fact that gender differences only tend to show up after years of schooling supports the need to consider social and environmental factors. As already noted, a number of studies have shown that stereotyping occurs in mathematics (Kiefer \& Sekaquaptewa, 2007; Li, 1999; Nosek, Banaji, \& Greenwald, 2002). Moreover, studies have shown that such stereotypes influence students' perceptions of their own abilities in mathematics (Bouchey \& Harter, 2005; Frome \& Eccles, 1998; Keller, 2001) as well as actual mathematics performance (Ben-Zeev, Fein, \& Inzlicht, 2005; Cadinu, Maass, Rosabianca, \& Kiesner, 2005; Quinn \& Spencer, 2001). While there are numerous potential variables to consider when investigating gender differences in mathematics, the issue of stereotyping implies that IBL in general and the MMM in particular may offer solutions for leveling the playing field. In an MMM class, the teacher becomes a facilitator who provides the problems, and the students drive the class by working on and presenting solutions to these problems. Perhaps this shift from a teaching style in which students are expected to listen and absorb information to a more active learning environment can present a novel experience for male and female students, creating an environment different from the traditional setting in which stereotyping may have favored the males. Laursen, et. al (2011) have argued that this different learning environment may level the playing field and remove the gender issue altogether, but if stereotyping and years of traditional classroom instruction has favored male students, they may in fact be more resistant to a different approach, a phenomena that seemed to occur in our classes.

\section{PURPOSE}

This study explored the use of a modified Moore method in an undergraduate Precalculus course at a midsize state university in the southeastern United States. Our specific version of a modified Moore method will be explained and referred to as "the MMM" throughout the remainder of this paper. By running a quasiexperimental study with three instructors, we sought to investigate the relationship between the method of instruction and the students' achievement in mathematics as well as the role that gender plays in this relationship. In this paper, we address the following research questions:

1. Will the students taught with the MMM perform better on a common final exam than the students taught in a traditional format?

2. Will the effects of the MMM on achievement differ by gender?

\section{METHODS AND PROCEDURES}

This study involved six sections of college precalculus at a midsized (approximately 6000 students) state university in the southeastern United States. The student body of the university is approximately 88\% Caucasian, 3\% African American, 3\% Hispanic, and 6\% other ethnicities with 59\% female and $41 \%$ male students. Each Precalculus section in this study had between 30 and 38 students.

\section{Course context}

The authors were the researchers and instructors for this study. We each taught one traditional precalculus section using a lecture format and a textbook by Stewart, Redlin, and Watson (2007) as well as one section using the MMM. In remainder of 
this paper, the sections that were taught with the MMM will be referred to by that label, and the label "Traditional" will be used to refer to the sections that were taught in a traditional lecture format. The instructors, i.e. the authors, will also be consistently referred to as Instructors 1,2 , and 3. These are randomly chosen identifiers, not the order of the authors on this paper, selected for consistent presentation of the results without identifying each specific instructor's results. Instructors 1 and 3 taught traditional sections in the Spring 2010 semester, while Instructor 2 piloted the MMM method. During the Fall 2010 semester, we switched roles with Instructor 2 teaching a traditional section and Instructors 1 and 3 teaching MMM sections. As students are allowed to register themselves for classes, it was not feasible to randomly assign students to sections. The students did not, however, know when they registered what type of teaching method would be used. Thus the study followed a quasi-experimental design with control and treatment groups used in a real-life setting lacking a random assignment of students to treatments.

In the MMM sections, we did not lecture on the material or present worked examples. The MMM sections were driven by a set of course notes consisting of definitions and problems designed to lead the students through the material. The content of the precalculus course in this study is mainly trigonometry and logarithmic and exponential functions, including the general features of functions, inverses, and graphs. Indeed, at the end of our course we expect our students will be able to:

- Determine if a function is one-to-one and find inverses of one-to-one functions;

- Apply the properties of exponents and logarithms to solve logarithmic and exponential equations;

- Use exponential functions to model growth and decay;

- Apply knowledge of vertical and horizontal asymptotes to curve sketching;

- Apply properties of geometric transformations to analyze the graphs of functions, including trigonometric functions;

- Apply trigonometric ratios and Pythagorean, double, half-angle, sum, difference, and co-function identities;

- Apply the Law of Sines and the Law of Cosines to solve for the unknown sides or angles of a triangle;

- Evaluate inverse trigonometric functions graphically, numerically, and algebraically.

Mahavier's (2007) Trigonometry notes were used and adapted for that portion of the course, and the material for the other topics was written by Karen Briggs. The notes contain the definitions of functions and concepts from the course, typically followed by a set of problems requiring the students to apply these definitions. A sample of these course notes is in the appendix. The problems were designed with the intent that each one could be solved using the basic definitions, results from previous problems, and prerequisite content knowledge. Furthermore, sequences of problems would lead the students to discover some mathematical property or theorem. For example, the notes contain the definition of the logarithmic functions, followed by 8 problems in which the students must use the definition to evaluate a logarithm of a given number. In addition to reinforcing the students understanding of the definition, these problems gradually elucidate an important property of logarithms. Another sequence of problems leads students to discover the rest of the properties of logarithms.

On the first day of class, the students were told to divide themselves into groups and given the first few pages of notes. They were given time to work on these problems, and then solutions were presented by volunteers. From that point on, a 
typical class consisted of the students presenting their proposed solutions to the problems that they had been given at the end of previous classes. Throughout the semester students were allowed to work in small groups, at their own discretion. The students often formed study-groups, small cohorts which worked together to complete the problem set or to study for the tests; instructors had no role in choosing theses groups. In general the student presentations drove the classes. Each student was responsible for making his or her best effort at solving a problem and for paying attention, asking questions, and discussing the problems as they were presented. To motivate the students to come to class prepared to present and discuss the homework, Instructors 1 and 3 counted the student presentations as $30 \%$ of the course grade, and Instructor 2 counted them as one-third of the grade. Other grades came from homework problems, exams, and class participation.

The main reason for using a student-centered, inquiry-based learning method is the belief that students will better understand and retain the knowledge that they have reasoned out for themselves and made sense of in their own way. For this reason, the students in the MMM sections were instructed that they could not seek help from any outside resources such as textbooks, internet materials, or help from people outside of the class. The students were allowed to work in groups on the assignments, and they were encouraged to meet with their instructor during office hours as needed. An important role of the instructor in an MMM section is to be able to take a problem that a student has seriously attempted but is unable to solve and break the problem into more manageable pieces or ask other questions that might lead the student toward a solution. This was occasionally done individually during office hours and for the entire class when no one could present a potential solution or approach to a problem in class.

In class, when no student was prepared to present a problem the instructor might break the problem into components and assist the students by asking leading questions. The instructor may also ask the students to form small groups and work on the problems together while the instructor circulated about the room, listening to conversations and contributing minimally when necessary. After completing a sequence of student presentations covering an important topic, the instructor would often summarize the findings for the entire class. Despite the quality of the student presentations and explanations, students would occasionally express confusion regarding the method of solutions. At these times, the instructor might create another similar problem and have the class participate in an interactive problemsolving session. This amounts to the instructor acting as scribe, writing on the board only what students say aloud and asking leading questions. Such questions usually referred to the previously presented solution. This can be done repeatedly until the methods of solution seem to be understood by the entire class.

\section{Final exam}

As a common measure of achievement, we used the list of course objectives from the department syllabus to create a final exam. This exam consists of 13 free response problems, with most problems having multiple parts, for a total of 42 separate items. A detailed common scoring rubric was developed with 200 possible points on the exam. To ensure grading consistency, the problems were divided with a given instructor grading the same set of problems for all six sections. As a single scale, these 42 items had a Cronbach's alpha of 0.898 . This alpha value indicates this scale is internally consistent and reliable; since content of the exam was selected based on our course objectives we believe this exam is a valid assessment of our students' course content knowledge. 


\section{RESULTS}

Table 1 shows the results of two-tailed, independent samples $t$-tests comparing the final exam scores of the students taught by the MMM and those taught by traditional lectures. The MMM students had higher average scores on the final exam overall and for two of the three instructors, but the difference was only significant for Instructor 2. Thus, ignoring gender, the MMM does not seem to have significantly affected the achievement of the majority of the students in our study. However, splitting the data by gender reveals some interesting results. The results in Table 2 show that there were no significant differences in the final exam scores for the males, but Table 3 provides evidence that the MMM was beneficial to the female students. For each instructor, the MMM females had a higher average score on the final exam than the females taught in the traditional lecture sections. The overall difference for females was highly significant $(p=0.002)$, and despite the relatively small sample sizes, the difference was significant for Instructor $3(p=0.005)$ and marginally significant for Instructor $2(p=0.073)$.

In addition to running the $t$-tests to compare exams scores by teaching styles within gender, we also ran an ANOVA on the four groups: Traditional Females, Traditional Males, MMM Females, and MMM males. The overall result of the omnibus test was significant $(F=5.317, p=0.002)$, and the post hoc Tukey HSD tests revealed significant differences in two cases. As detected by the $t$-tests, the MMM females performed significantly better than the Traditional females $(p=0.011)$ and the effect size as measured by Cohen's $d(1988)$ is medium $(d=0.609)$. In addition, the MMM females performed significantly better than the MMM males $(p=0.002)$

Table 1. Results of t-tests comparing final exam scores by treatment

\begin{tabular}{|c|c|c|c|c|c|}
\hline \multicolumn{6}{|c|}{ Total } \\
\hline Group & $\mathbf{M}$ & SD & $\mathbf{n}$ & $\mathbf{t}$ & $\mathbf{p}$ \\
\hline МMM & 124.8 & 34.4 & 92 & -1.416 & 0.160 \\
\hline Traditional & 117.7 & 35.3 & 101 & & \\
\hline \multicolumn{6}{|c|}{ Instructor 1} \\
\hline МMM & 111.8 & 29.2 & 31 & 0.690 & 0.499 \\
\hline Traditional & 117.8 & 39.9 & 34 & & \\
\hline \multicolumn{6}{|c|}{ Instructor 2} \\
\hline MMM & 136.5 & 27.7 & 32 & -2.129 & 0.037 \\
\hline Traditional & 120.0 & 35.0 & 34 & & \\
\hline \multicolumn{6}{|c|}{ Instructor 3} \\
\hline MMM & 125.8 & 41.8 & 29 & -1.117 & 0.269 \\
\hline Traditional & 115.2 & 31.3 & 33 & & \\
\hline
\end{tabular}

Table 2. Results of t-tests comparing final exam scores by treatment for male students

\begin{tabular}{|c|c|c|c|c|c|}
\hline \multicolumn{6}{|c|}{ Total } \\
\hline Group & $\mathbf{M}$ & SD & $\mathbf{n}$ & $\mathbf{t}$ & $\mathbf{p}$ \\
\hline МMM & 110.3 & 33.9 & 41 & 1.188 & 0.238 \\
\hline Traditional & 119.7 & 36.0 & 38 & & \\
\hline \multicolumn{6}{|c|}{ Instructor 1} \\
\hline MMM & 105.6 & 27.4 & 17 & 1.292 & 0.211 \\
\hline Traditional & 124.4 & 48.3 & 14 & & \\
\hline \multicolumn{6}{|c|}{ Instructor 2} \\
\hline MMM & 125.9 & 25.7 & 9 & -0.868 & 0.396 \\
\hline Traditional & 114.5 & 34.4 & 12 & & \\
\hline \multicolumn{6}{|c|}{ Instructor 3} \\
\hline МMM & 106.3 & 42.8 & 15 & 1.057 & 0.303 \\
\hline Traditional & 119.3 & 19.1 & 12 & & \\
\hline
\end{tabular}


Table 3. Results of t-tests comparing final exam scores by treatment for female students

\begin{tabular}{|c|c|c|c|c|c|}
\hline \multicolumn{6}{|c|}{ Total } \\
\hline Group & $\mathbf{M}$ & SD & $\mathbf{n}$ & $\mathbf{t}$ & $\mathbf{p}$ \\
\hline МMM & 136.5 & 30.5 & 51 & -3.251 & 0.002 \\
\hline Traditional & 116.5 & 35.1 & 63 & & \\
\hline \multicolumn{6}{|c|}{ Instructor 1} \\
\hline МMM & 119.4 & 30.5 & 14 & -0.563 & 0.577 \\
\hline Traditional & 113.2 & 33.4 & 20 & & \\
\hline \multicolumn{6}{|c|}{ Instructor 2} \\
\hline MMM & 140.7 & 27.9 & 23 & -1.841 & 0.073 \\
\hline Traditional & 123.0 & 35.7 & 22 & & \\
\hline \multicolumn{6}{|c|}{ Instructor 3} \\
\hline MMM & 146.8 & 29.5 & 14 & -3.016 & 0.005 \\
\hline Traditional & 112.9 & 36.7 & 21 & & \\
\hline
\end{tabular}

and the effect size is considered large $(d=0.826)$. No other pairwise comparison was significantly different.

\section{DISCUSSION}

As previously noted, gender differences in achievement and attitudes have been widely discussed in science, technology, engineering, and mathematics (STEM) education. As gender may affect one's preferred learning style, we felt that it was important to examine whether or not there were different results when we separated the data into male and female groups. This was indeed the case. After one semester of the study, we found that the MMM section had significantly higher scores on the common final exam than the two control sections (Briggs, Bailey, \& Cooper, 2011). Those results, however, did not take into account the instructor differences or possible gender differences. In fact, Instructor 2's MMM class was nearly three-fourths female, whereas the two control sections were each approximately $60 \%$ female (very close to the universities gender distribution).

When we analyzed the data from two semesters, it was evident that there were major differences between the performance of the males and females as reported in this paper. When dividing the students by gender and type of instruction, we found that there were no significant differences between the final exam results for males and females in the traditional sections. However, the females taught with the MMM did significantly better than the females in the traditional sections and the males in the MMM sections. Thus, the use of the MMM in our precalculus classes seems to have created a gender gap in favor of the females.

The results of this study lead to the question, "Why did the MMM seem to improve the achievement of female students, but somewhat hurt the achievement of the male students?" Since we were unable to conduct a random experiment it is possible that the females in the MMM sections were just better students. We do not think that is the case. Though our assignment of teaching methods was not random, we did run the quasi-experiment across three instructors, reducing the likelihood that the more talented females and less talented males enrolled in the MMM sections in each case. We also looked at the students' scores from the mathematics section of the SAT and found no significant differences between the four groups when tested with an ANOVA $(F=0.676, p=0.568)$. We think a more plausible explanation for the gender differences that we observed lies in the theory of stereotyping (Steele, 1997). If it is true that the traditional $\mathrm{K}-12$ mathematics experiences lead to stereotyping mathematics as a male domain, then the male students have the most to lose when faced with a different teaching approach. Each of us can think of several male students in our classes who expressed disdain for the method, rarely volunteered for presentations or participated in class discussions, and usually came to class with 
no work completed on the assignments. While we would not claim that the majority of the female students were thrilled with the idea of an inquiry-based mathematics class with no lectures, very few females openly complained about the method, and more females seemed to come prepared to share their work in class.

We think that the MMM is consistent with the well established constructivist theory of learning and should be a viable method to promote deep conceptual learning for males and females. However, students' attitudes and willingness to participate are essential ingredients for success. Our initial findings indicate that gender may play a key role in a student's openness to the MMM method. As instructors, part of our job is to motivate students to embrace our teaching styles and participate in class activities. If the results of our study are indeed due to stereotyping, motivating male students to participate in the MMM in introductory level mathematics classes may be tougher than motivating the females.

\section{LIMITATIONS AND RECOMMENDATIONS FOR FUTURE STUDY}

As with any study, there are several limitations and questions remaining for future study. As noted in the discussion, we were unable to randomly assign the students to sections, preventing a true experimental design, but we were able to strengthen the power of our design to some extent by having control and treatment sections for three different instructors. A future study could strengthen the nonrandom design further by including a pre-test to assess the students' prior knowledge of the specific course material. We did look at the students' SAT scores, but a course specific pre-test would be more informative. We also believe that comparing fall semester to spring semester students is a possible limitation of this study. In our fall Precalculus classes, the majority of the students are first semester college students, taking their first college classes. Perhaps these students have different expectations than students in the spring who have had at least one semester of college courses. Students with more college experience may be more receptive to the MMM. A longer study could compare students with similar levels of college experience.

Because we were not expecting gender differences when we initially planned our study of the MMM, we did not collect empirical data specifically to investigate possible sources of gender differences. This should be addressed in future research through both qualitative and quantitative methods. Open- ended surveys and student interviews could shed light onto this issue.

Our study was also limited to using the common final exam as the sole measure of student achievement. This exam was written to reflect our common course syllabus and content that we feel is typical of college precalculus courses. Future studies could look at more types of problems and other forms of assessment. Performance in Calculus I would be an excellent measure of success. This was problematic in our study due to the fact that a large number of our Precalculus students do not actually take a college calculus course. Our Precalculus course serves as the terminal mathematics requirement for many majors, and many of our mathematics and science majors take Calculus I as their first college mathematics class. Thus, we have not been able to collect a large enough sample of Calculus I grades for any meaningful analysis at this point. Researchers with a larger population of Precalculus students transitioning to Calculus I may wish to investigate the effects of the MMM in Precalculus on students' success in Calculus I.

Finally, student populations vary from school to school, and we hope that the results of this study will encourage teachers and researchers to consider using an inquiry-based approach in other classes at other settings. Learning in a MMM class is a challenge which requires hard work from the students. Throughout history many students have sought a "royal road" to knowledge, and part of our job as educators is 
to teach them that as with physical fitness, mental fitness and agility can only be earned through hard work. More studies and reports of the benefits of inquiry-based learning would be valuable evidence that teachers could present to students to argue this case.

\section{ACKNOWLEDGEMENTS}

We would like to thank the Educational Advancement Foundation for funding this research.

\section{REFERENCES}

Benbow, C. P. (1988). Sex differences in mathematical reasoning ability in intellectually talented preadolescents: Their nature, effects, and possible causes. Behavioral and Brain Sciences, 11(2), 169-232. doi: 10.1017/S0140525X00049244

Ben-Zeev, T., Fein, S., \& Inzlicht, M. (2005). Arousal and stereotype threat. Journal of Experimental Social Psychology, 41(2), 174-181. doi: 10.1016/j.jesp.2003.11.007

Betz, N. E., \& Hackett, G. (1983). The relationship of mathematics self-efficacy expectations to the selection of science-based college majors. Journal of Vocational Behavior, 23(3), 329. doi: 10.1016/0001-8791(83)90046-5

Bouchey, H. A., \& Harter, S. (2005). Reflected appraisals, academic self-perceptions, and math/science performance during early adolescence. Journal of Educational Psychology, 97(4), 673-687. doi: 10.1037/0022-0663.97.4.673

Briggs, K. S., Bailey, B., \& Cooper, T. E. (2001). Is Moore better (in precalculus)? American Mathematical Society's Notices, 58(7), 963-965.

Byrnes, J. P. (2005). Gender differences in math: Cognitive processes in an expanded framework. In A. Gallagher \& J. Kaufman (Eds.), Gender differences in mathematics: An integrative psychological approach (pp. 73-98). New York, NY: Cambridge University Press. doi: $10.1017 /$ CB09780511614446.005

Byrnes, J. P., \& Takahira, S. (1993). Explaining gender differences on SAT math items. Developmental Psychology, 29(5), 805-810. doi: 10.1037/0012-1649.29.5.805

Cadinu, M., Maass, A., Rosabianca, A., \& Kiesner, J. (2005). Why do women underperform under stereotype threat? Evidence for the role of negative thinking. Psychological Science, 16(7), 572- 578. doi: 10.1111/j.0956-7976.2005.01577.x

Chalice, D. R. (1995). How to teach a class by the modified Moore method. American Mathematical Monthly, 102(4), 317-321. doi: 10.2307/2974951

Cobb, P. (1994). Where is the mind? Constructivist and sociocultural perspectives on mathematical development. Educational Researcher, 23(7), 13-19. doi: 10.3102/0013189X023007013

Cohen, J. (1988). Statistical Power Analysis for the Behavioral Sciences (2nd ed.). Hillsdale, NJ: Erlbaum.

Cohen, D. W. (1982). A modified Moore method for teaching undergraduate mathematics. American Mathematical Monthly, 89(7), 473-474, 487-490.

Confrey, J. (1990). What constructivism implies for teaching. In R. B. Davis, C. A. Maher \& N. Noddings (eds.), Constructivist views on the teaching and learning of mathematics (JRME monograph 4) (pp. 107-122). Reston, VA : NCTM.

Dochy, F., Segers, M., Van den Bossche, P., \& Gijbels, D. (2003). Effects of problem-based learning: A meta-analysis. Learning and Instruction, 13, 533-568. doi:10.1016/S0959-4752(02)00025-7

Fennema, E., \& Sherman, J. (1977). Sex-related differences in mathematics achievement, spatial visualization, and affective factors. American Educational Research Journal, 14, 51-71. doi: 10.3102/00028312014001051

Frome, P. M., \& Eccles, J. S. (1998). Parents' influence on children's achievement-related perceptions. Journal of Personality and Social Psychology, 74(2), 435-452. doi: 10.1037/0022-3514.74.2.435

Hmelo-Silver, C., Duncan, R., \& Chinn, C. (2007). Scaffolding and achievement in problembased and inquiry learning: A response to Kirschner, Sweller, and Clark (2006). Educational Psychologist, 42(2), 99-107. doi: 10.1080/00461520701263368 
Jones, F. B. 1977. The Moore method. American Mathematical Monthly, 84(4), 273-278.

Keller, C. (2001). Effects of teachers' stereotyping on students' stereotyping of mathematics as a male domain. Journal of Social Psychology, 141(2), 165-173. doi: 10.1080/00224540109600544

Kiefer A. K., \& Sekaquaptewa D. (2007). Implicit stereotypes, gender identification, and mathrelated outcomes: A prospective study of female college students. Psychological Science, 18(1), 13-18. doi: 10.1111/j.1467-9280.2007.01841.x

Kirschner, P. A., J. Sweller, \& R. E. Clark. (2006). Why minimal guidance during instruction does not work: An analysis of the failure of constructivist, discovery, problem-based, experiential, and inquiry-based teaching. Educational Psychologist, 41(2), 75-86. doi: $10.1207 /$ s15326985ep4102_1

Kuhn, D. (2007). Is direct instruction the answer to the right question? Educational Psychologist, 42, 109-113. doi: 10.1080/00461520701263376

Laursen, S., Hassi, M., Kogan, M., Hunter, A., \& Weston, T. (2011). Evaluation of the IBL mathematics project: Student and instructor outcomes of inquiry-based learning in college mathematics. Boulder, CO: University of Colorado Boulder, Assessment \& Evaluation Center for Inquiry-Based Learning in Mathematics. Retrieved from http://colorado.edu/eer/research/documents/IBLmathReportALL_050211.pdf

Li, Q. (1999). Teachers' beliefs and gender differences in mathematics: A review. Educational Research, 41(1), 63-76. doi: 10.1080/0013188990410106

Lindberg, S. M., Hyde, J. S., \& Peterson, J. L. (2010). New trends in gender and mathematics performance: A meta-analysis. Psychological Bulletin, 136(6), 1123-1135. doi: $10.1037 / \mathrm{a} 0021276$

Mahavier, W. T. (1997). A gentle discovery method. College Teaching, 45, 132-135. doi: $10.1080 / 87567559709596214$

Mahavier, W. T. (2007). Trigonometry. Journal of Inquiry-Based Learning in Mathematics, 1, n/a. Retrieved from http://www.jiblm.org/downloads/jiblmjournal/V070101/V070101.pdf

Nosek, B. A., Banaji M. R., \& Greenwald A. G. (2002). Math = male, me = female, therefore math $\neq$ me. Journal of Personality and Social Psychology, 83(1), 44-59. doi: 10.1037/0022-3514.83.1.44

Pallas, A. M., \& Alexander, K. L. (1983). Sex differences in quantitative SAT performance: new evidence on the differential coursework hypothesis. American Educational Research Journal, 20(2), 165-182. doi: 10.3102/00028312020002165

Quinn, D. M., \& Spencer, S. J. (2001). The interference of stereotype threat with women's generation of mathematical problem-solving strategies. Journal of Social Issues, 57(1), 55-71. doi: 10.1111/0022-4537.00201

Reichardt, C. S. (2009). Quasi-experimental design. In R. E. Millsap \& A. Maydeu-Olivares (eds.), The SAGE Handbook of Quantitative Methods in Psychology (pp. 46-71). Thousand Oaks, CA: Sage. doi: 10.4135/978085702094

Schmidt, H. G., Loyens, S. M. M., van Gog, T., \& Paas, F. (2007). Problem-based learning is compatible with human cognitive architecture: Commentary on Kirschner, Sweller, and Clark (2006). Educational Psychologist, 42, 91-97. doi: 10.1080/00461520701263350

Steele, C. M. (1997). A threat in the air: How stereotypes shape intellectual identity and performance. American Psychologist, 52(6), 613-629.

Stewart, J., Redlin, L., \& Watson, S. (2007). Precalculus: Mathematics for Calculus (5 ${ }^{\text {th }}$ ed.). Pacific Grove, CA: Brooks/Cole.

Traylor, D. R. (1972). Creative Teaching: The Heritage of R. L. Moore. Houston, TX: University of Houston.

von Glasersfeld, E. (2003). An Exposition of Constructivism: Why Some Like It Radical. Retrieved from http://www.oikos.org/constructivism.htm

Whyburn, L. S. (1970). Student oriented teaching - the Moore method. American Mathematical Monthly, 77(4), 351-359.

Zitarelli, D. E. (2004). The origins and early impact of the Moore method. American Mathematical Monthly. 111(6), 465-486.

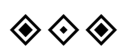




\section{Sample Course Notes}

\section{Appendix}

Definition 1. If $\$ P$ is invested into an account that earns $r \%$ (expressed as a decimal) interest compounded continuously, then the amount in the account after $t$ years is given by $A(t)=P e^{r t}$.

Problem 1. Suppose that $\$ 3500$ is invested into an account that earns $5 \%$ annual interest, compounded continuously.

a. Find the value of the account after 4 years.

b. Set up the equation to determine after how many years the account will be worth $\$ 5000$ ? Are you able to solve this problem?

\section{LOGARITHMIC FUNCTIONS}

Definition 2. The inverse of the exponential function $y=b^{x}$ is called the logarithmic function with base $\boldsymbol{b}$ and is denoted by $y=\log _{b} x$, for $x>0$ and $0<b \neq 1$. This means that $\log _{b} x$ is "the power of $\mathbf{b}$ which yields $x^{\prime \prime}$.

Problem 2. Reflect the graph of $y=b^{x}$ about the line $y=x$. The reflection is the graph of what function?

Problem 3. Use your graph above to determine the following properties of the logarithmic function $y=\log _{b} x$. (Recall that the inverse is obtained by reflecting the given graph across the line $y=x$. Symbolically, this is equivalent to swapping the $x^{\prime}$ s and the $y^{\prime}$ s.)

a. Domain:

b. Range:

c. $x$-intercept:

d. Increasing or decreasing?
i. $\quad$ if $b>1$ :
ii. if $0<b<1$ :

e. Asymptote: (The exponential function had a horizontal

\section{Definition 3.} asymptote, so the logarithmic function should have a vertical asymptote.)

- When $b=e$, we write $y=\ln x$ rather than $y=\log _{e} x$. We call $y=\ln x$ the natural logarithmic function.

- When $b=10$, we write $y=\log x$ rather than $y=\log _{10} x$. We call $y=\log _{10} x$ the common logarithmic function.

Problem 4. Use the definition of the logarithm to evaluate the following. Remember that $\log _{b} x$ means "the power of $b$ that yields $x$ ".
a. $\log _{5} 125$
b. $\log _{3} \frac{1}{9}$
c. $\log _{2} \sqrt{32}$
d. $\log 0.0001$
e. $\log _{32} 2$
f. $\log _{7} 7^{3}$
g. $\ln e^{3}$
h. $\log _{5} 1$

Problem 5. Generalize what you just discovered in parts (f) - (h):
a. $\log _{b} 1=$
b. $\log _{b} b^{x}=$ (The logarithmic function undoes the exponential function.) 


\section{LAWS OF LOGARITHMS}

Definition 4. The logarithmic equation $y=\log _{b} x$ can be written in exponential form $b^{y}=x$. Both equations are equivalent.

Problem 6. Let $M$ and $N$ be positive real numbers and set $x=\log _{b} M$ and $y=\log _{b} N$.

a. Write both of these logarithmic equations in exponential form and consider the product $M N$. Your simplified answer should be an exponential equation.

b. Write the equation you just found in $\underline{\operatorname{logarithmic} \text { form }}$ and replace $x$ with $\log _{b} M$ and $y$ with $\log _{b} N$.

Definition 5. The equation you just found is called the Multiplication Rule for Logarithms.

Problem 7. Apply the same procedure as in Problem 38, but consider the quotient $M / N$.

Definition 6. The equation you just found is called the Quotient Rule for Logarithms.

Problem 8. Apply the same procedure as in Problem 38, but consider $M^{c}$ where $c$ is a constant.

Definition 7. The equation you just found is called the Power Rule for Logarithms. 